\title{
Correcting the MoCA for Education: Effect on Sensitivity
}

\author{
Genevieve Gagnon, Kevin T. Hansen, Sarah Woolmore-Goodwin, Iris Gutmanis, \\ Jennie Wells, Michael Borrie, Jennifer Fogarty
}

\begin{abstract}
Objective: The goal of this study was to quantify the impact of the suggested education correction on the sensitivity and specificity of the Montreal Cognitive Assessment (MoCA). Method: Twenty-five outpatients with dementia and 39 with amnestic mild cognitive impairment (aMCI) underwent a diagnostic evaluation, which included the MoCA. Thirty-seven healthy controls also completed the MoCA and psychiatric, medical, neurological, functional, and cognitive difficulties were ruled out. Results: For the total MoCA score, unadjusted for education, a cut-off score of 26 yielded the best balance between sensitivity and specificity $(80 \%$ and $89 \%$ respectively) in identifying cognitive impairment (people with either dementia or aMCI, versus controls). When applying the education correction, sensitivity decreased from $80 \%$ to $69 \%$ for a small specificity increase ( $89 \%$ to $92 \%$ ). The cut-off score yielding the best balance between sensitivity and specificity for the education adjusted MoCA score fell to 25 (61\% and 97\%, respectively). Conclusions: Adjusting the MoCA total score for education had a detrimental effect on sensitivity with only a slight increase in specificity. Clinically, this loss in sensitivity can lead to an increased number of false negatives, as education level does not always correlate to premorbid intellectual function. Clinical judgment about premorbid status should guide interpretation. However, as this effect may be cohortspecific, age and education corrected norms and cut-offs should be developed to help guide MoCA interpretation.
\end{abstract}

RÉSUMÉ: Effet sur la sensibilité du MoCA d'une correction pour tenir compte du niveau de scolarité. Objectif : Le but de cette étude était de quantifier l'impact d'une correction pour tenir compte du niveau de scolarité sur la sensibilité et la spécificité du Montreal Cognitive Assessment (MoCA). Méthode : vingt-cinq patients d'une clinique externe atteints de démence et 39 patients présentant un déficit cognitif léger amnésique (DCLa) ont complété le MoCA au cours d'une évaluation diagnostique. Trente-sept participants contrôles sains (sans problèmes psychiatriques, médicaux, neurologiques, fonctionnels et/ou cognitifs) ont également complété le MoCA. Résultats : Pour le score total au MoCA, sans la correction pour tenir compte du niveau de scolarité, le meilleur équilibre entre sensibilité et spécificité (respectivement de $80 \%$ et $89 \%$ ) pour l'identification de la présence d'un déficit cognitif (démence ou DCLa) était trouvée avec un seuil de 26. Après avoir appliqué la correction pour le niveau de scolarité, la sensibilité diminuait de $80 \%$ à $69 \%$ en échange d'une légère augmentation de la spécificité, ( $89 \%$ à $92 \%$ ). Un seuil de 25 donnait alors le meilleur équilibre entre la sensibilité et la spécificité lorsque le score du MoCA était corrigé pour tenir compte du niveau de scolarité, soit $61 \%$ et $97 \%$ respectivement. Conclusion : Un ajustement du score total du MoCA pour tenir compte du niveau de scolarité avait un donc effet délétère sur la sensibilité en échange de seulement qu'une très légère amélioration au niveau de la spécificité. En clinique, cette perte de sensibilité peut donner lieu à une inflation du nombre de faux positifs car le niveau de scolarité n'est pas toujours corrélé à la fonction intellectuelle prémorbide. Le jugement clinique de l'état prémorbide devrait guider l'interprétation du test. il est à noter que cet effet pourrait être spécifique à la cohorte étudiée et que des normes et des seuils corrigés pour tenir compte de l'âge et du niveau de scolarité devraient être développées afin de guider l'interprétation du MoCA.

Can J Neurol Sci. 2013; 40: 678-683

The MoCA is a recently published and increasingly popular screening test for use in detecting cognitive impairment among older adults. ${ }^{1}$ Mild cognitive impairment (MCI) is considered an intermediate clinical state between normal cognitive aging and dementia where patients experience memory difficulties that are greater than expected for their age and education. In addition, individuals with MCI have less impairment in everyday functioning as compared to those with dementia. ${ }^{2}$ Individuals suffering from MCI are an at-risk group, with up to $80 \%$ of individuals with MCI progressing to dementia within five years. ${ }^{3}$ For this reason, it is important to detect early memory impairment and to monitor cognitive function over time. ${ }^{4}$

Comprehensive geriatric assessments in tertiary care (e.g. memory disorder clinics), including neuropsychological evaluations, are often used to diagnose MCI. However, individuals concerned about their memory are not always able to access tertiary care memory clinics in a timely fashion. ${ }^{5}$ As such, a cognitive screening measure that is high in sensitivity and specificity is required for use by primary care physicians to decide who needs a more comprehensive evaluation. ${ }^{1}$

From the Centre for Addiction and Mental Health (GG); Department of Psychiatry (GG), University of Toronto, Toronto; Lawson Health Research Institute at St. Joseph's Health Care (IG, JW, MB, JF), Specialized Geriatric Services (KTH, SWG, IG, JW, MB, JF), St. Joseph's Health Care London; Division of Geriatric Medicine (IG, JW, MB, JF), Department of Psychiatry (IG, JF), Faculty of Medicine, Department of Epidemiology and Biostatistics (IG), Schulich School of Medicine and Dentistry, Western University, London, Ontario; Consortium of Canadian Centres for Clinical Cognitive Research (C5R) (MB), Calgary, Alberta, Canada.

Received January 10, 2013. Final Revisions Submitted April 30, 2013. Correspondence to: Jennifer Fogarty, St. Joseph's Health Care London, 801 Commissioners Road East, London, Ontario, N6C 5J1, Canada.

Email: jennifer.fogarty@sjhc.london.on.ca. 
To detect cognitive impairment ${ }^{2-4}$ at an early stage, the Montreal Cognitive Assessment $\left(\mathrm{MoCA}^{1}\right)$ represents a marked improvement over the widely used Mini-Mental State Examination $\left(\mathrm{MMSE}^{6}\right.$ ) as older adults living with MCI often still perform in the normal range on the MMSE ${ }^{1}$. Initial MoCA research suggested that with a cut-off score of less than 26/30, sensitivity for individuals with MCI was $90 \%$ (compared to $18 \%$ for the MMSE) and specificity was $87 \%$ (compared to $100 \%$ for the MMSE). ${ }^{1}$ Since this time, the MoCA has been validated as a more sensitive measure of cognitive difficulties than the MMSE in different populations. ${ }^{7,8}$ The MoCA is relatively simple to administer and to interpret, however, this tool does not account for pre-morbid functioning (e.g. intellectual function, occupational status) or specific numbers of years of education. This is an important drawback, as it limits the clinician's ability to determine if there is a decline in cognitive abilities greater than expected for one's age and education. People with lower levels of education tend to score lower on the MoCA compared to people with higher levels of education. ${ }^{1,9-11}$ In an attempt to compensate for this disadvantage, it has been proposed that one point be added to the total MoCA score, for patients who have 12 or fewer years of education. ${ }^{1}$ One recent community and hospital-based study suggested that the recommended 1-point education correction could decrease the reliability of the MoCA. ${ }^{9}$ However, to our knowledge, there are no published papers systematically comparing sensitivity and specificity of the "corrected" and "uncorrected" scores. Given that education is a known moderator of risk of cognitive decline, ${ }^{12}$ adding an extra point to a group of individuals with a high school education or less minimizes the benefit of education in the larger group. This study assessed the effect of the widely used 1-point correction on the sensitivity and the specificity of the MoCA in a hospital-based population.

\section{METHOD}

Twenty-five individuals with dementia (22 individuals with probable Alzheimer's Disease [AD] and 3 with mixed ADVascular dementia [DSM IV-TR ${ }^{13}$ ]) seen in a tertiary-care based memory clinic between 2007 and 2011 were included in the study. Thirty-nine individuals with amnestic mild cognitive impairment $(\mathrm{aMCI})^{3}$, single and multiple domains were also included. All participant data came from individuals presenting to specialty geriatric outpatient clinical and research programs in London, Ontario. Following approval from Western University's Research Ethics Board, participants provided written informed consent to have their information entered into a research database. Data were collected from retrospective research and clinical chart reviews. Diagnoses of either dementia or aMCI were based on an interview with the participant and an informant, when available, about history of cognitive concerns and functional decline and a review of all available medical, neurological, psychiatric, and neuropsychological test data. The neuropsychological test battery was completed within six months of the MoCA and MMSE scores, but in most cases, all assessments were completed on the same day. A licensed clinical neuropsychologist (JF) or her psychometrist assistant, under the supervision of the neuropsychologist, completed the neuropsychological evaluation. All participants had a functional use of the English language (using English in their work and everyday social interactions). Participants were asked to identify their highest level of education. If this was less than high school, participants were asked to identify the highest grade they completed. High school graduates were assigned 12 years of education. Among those who had more than high school education, number of years completed in undergraduate programs was recorded (i.e. a completed four-year bachelor's degree would be assigned 16 years of education, while a threeyear degree would be assigned 15 years of education). Those who had received a Master's degree were assigned 18 years of education and those who had a Doctorate were assigned 20 years of education. ${ }^{14}$ Participants were excluded if there was a history of major psychiatric difficulties that could have an impact on cognitive function, current major depressive episode, or if they were currently taking psychotropic medication.

Thirty-seven healthy controls (HC) were recruited from two sources, from advertisements posted at various community centres and through a newspaper advertisement. All participants completed the Dartmouth Memory and Aging Telephone Screen $^{15}$ with a research assistant who had extensive geriatric clinical experience (S.W-G.). Participants were excluded if there were any identified psychiatric, neurological, or medical conditions that could affect cognition, or if they indicated that they were taking any psychotropic medications. Controls also had an MMSE score of 27 or higher, and no significant concerns about their memory. All controls had a Clinical Dementia Rating Scale $(\mathrm{CDR})^{16}$ score of " 0 " based on an interview with themselves and an informant. A licensed clinical neuropsychologist (JF), trained research assistant, or a nurse clinician administered the CDR. The latter two individuals had extensive experience with geriatric populations. All three individuals successfully completed the on-line training module for the Clinical Dementia Rating Scale through the Alzheimer's Disease Research Center through the Washington University School of Medicine. Consensus on diagnosis was reached between two neuropsychologists, independent of the MoCA score.

Univariate analyses were conducted to determine the frequency distributions associated with all study variables. Next, a one-way analysis of variance was used to identify any between-group demographic differences. Because the total MoCA score is used to detect any cognitive impairment, for this paper we combined the information for those who were diagnosed as presenting with either aMCI or dementia. T-tests or chi-square tests were used, as appropriate, to determine if there were any differences between these two study groups. A logistic regression was conducted to determine the predictive value of the MoCA score on the diagnosis of cognitive impairment ( $\mathrm{HC}$ versus aMCI + dementia).

Logistic regression was also used to determine the impact of various possible covariates including education, sex, and age on the relationship between the MoCA score and the diagnosis of cognitive impairment. To help further understanding of the possible impact of education on the relationship between MoCA score and disease status, education was conceptualized as a continuous variable as well as a categorical variable. Similar to Nasreddine's work, education was dichotomized (less than high school versus completed high school or more). These analyses were conducted using SPSS (SPSS 19.0 for Windows, 2011). To 
Table 1: Demographic characteristics of the group

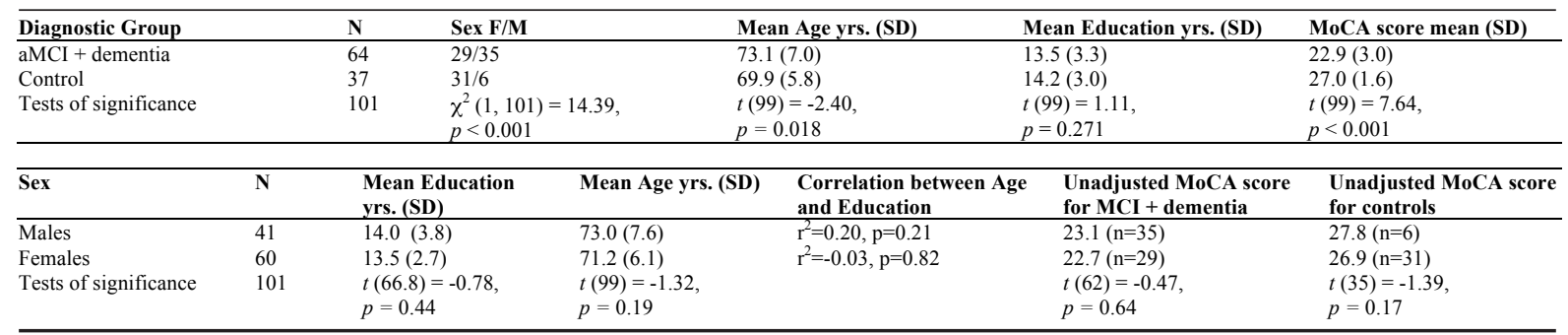

$\mathrm{N}=$ sample size; $\mathrm{F}=$ female $\mathrm{M}=$ male; yrs. = years; $\mathrm{SD}=$ Standard Deviation; $\chi 2$ = chi-square test; number in brackets are the degrees of freedom; $t=\mathrm{t}$-test.

examine further the impact of significant covariates, receiver operating characteristic (ROC) curves were generated for unadjusted MoCA scores, for scores adjusted for educational attainment as suggested by the instructions of the tests (MoCA version 7.1) and by any covariates that significantly impacted the relationship between the MoCA score and disease status. For each ROC curve, the sensitivity and specificity as well as the area under the ROC curve (AUC) were determined. These data were analysed using MedCalc (http://www.medcalc.org).

\section{ReSUlts}

Population descriptors are presented in Table 1. The cognitively impaired group differed from the HC group in terms of mean age and mean MoCA score. However, the two study groups did not differ significantly in terms of mean years of education. Further, while $54.7 \%$ of the cognitively impaired group were males, this proportion fell to $16.2 \%$ in the HC group. As education and age were identified at possible covariates in the relationship between MoCA score and disease status, the relationships between sex, age, and education were examined in detail. As seen in Table 1, neither mean age nor education differed significantly by sex. As well, the correlation between age and education was not statistically significant for either sex. For the unadjusted total MoCA score, a cut-off score of less than 26 ( $\leq 25$ indicating impairment) yielded the best balance between sensitivity and specificity $(80 \%$ and $89 \%$ respectively;

Table 2: Sensitivity and specificity analysis by unadjusted and adjusted MoCA scores

\begin{tabular}{|c|c|c|c|c|}
\hline \multicolumn{5}{|c|}{ Total MoCA Score } \\
\hline Criterion & Sensitivity $^{\mathrm{a}}$ & Specificity $^{\mathrm{a}}$ & Positive Predictive Value & Negative Predictive Value \\
\hline$<16$ & 0.00 & 100.00 & --- & --- \\
\hline$\leq 23$ & 59.38 & 100.00 & 1.00 & --- \\
\hline$\leq 24$ & 67.19 & 91.89 & 0.93 & 0.62 \\
\hline$\leq \mathbf{2 5}$ & *79.69 & *89.19 & 0.93 & 0.72 \\
\hline$\leq 26$ & 87.50 & 59.46 & 0.79 & 0.73 \\
\hline$\leq 27$ & 93.75 & 35.14 & 0.71 & 0.76 \\
\hline$\leq 28$ & 98.44 & 21.62 & 0.68 & 0.89 \\
\hline$\leq 29$ & 100.00 & 5.41 & 0.65 & 1.00 \\
\hline$\leq 30$ & 100.00 & 0.00 & 0.63 & --- \\
\hline \multicolumn{5}{|c|}{ Total MoCA Score (adjusted) } \\
\hline Criterion & Sensitivity ${ }^{\mathrm{a}}$ & Specificity $^{\mathrm{a}}$ & Positive Predictive Value & Negative Predictive Value \\
\hline$<17$ & 0.00 & 100.00 & --- & --- \\
\hline$\leq 23$ & 48.44 & 100.00 & 1.00 & --- \\
\hline$\leq 24$ & * 64.06 & * 97.30 & 0.98 & 0.61 \\
\hline$\leq \mathbf{2 5}$ & 68.75 & 91.89 & 0.94 & 0.63 \\
\hline$\leq 26$ & 79.69 & 70.27 & 0.82 & 0.67 \\
\hline$\leq 27$ & 92.19 & 54.04 & 0.78 & 0.80 \\
\hline$\leq 28$ & 96.87 & 24.32 & 0.69 & 0.82 \\
\hline$\leq 29$ & 98.44 & 10.81 & 0.66 & 0.80 \\
\hline$\leq 30$ & 100.00 & 0.00 & 0.63 & --- \\
\hline Sex & \multicolumn{2}{|c|}{ AUC MoCA Score } & \multicolumn{2}{|c|}{ AUC MoCA Score (adjusted) $\dagger$} \\
\hline Males & \multicolumn{2}{|c|}{0.929} & \multicolumn{2}{|c|}{0.900} \\
\hline Females & \multicolumn{2}{|r|}{0.883} & \multicolumn{2}{|r|}{0.882} \\
\hline Both Sexes & \multicolumn{2}{|r|}{0.885} & \multicolumn{2}{|r|}{0.871} \\
\hline
\end{tabular}

AUC: Area under the curve. ${ }^{a}$ Entries in bold are the recommended cut-points for the

MoCA, those with an asterisk (*) yield the best balance between specificity and sensitivity; $\dagger$ in all cases, the area under the roc curve is significantly different from 0.5 . 
AUC $=0.885, \mathrm{p}<0.001)$ in identifying people with a cognitive impairment versus HC (see Table 2). This was consistent with the cut-off score identified in the original validation study. As well, with this cut-off score $92.7 \%$ per cent of people with a positive test result had cognitive impairment (positive predictive value: 0.93 ) and $71.7 \%$ per cent of people with a negative test result did not have cognitive impairment (negative predictive value: 0.72 ). As well, in this study population, the prevalence of cognitive impairment was $63 \%$.

The 1-point correction for education was then applied to the total MoCA score. While $45.9 \%$ of the total population had 12 or less years of education, only $5.4 \%$ of the population had less than ten years of education. After applying this correction to the total MoCA score and using a cut-off of less than 26, the sensitivity decreased from 80 to $69 \%$ while specificity increased by only a few points, from 89 to $92 \%$. Further, the positive predictive value increased slightly $(93.6 \%$ versus $92.7 \%)$ but the negative predictive value fell $(71.7 \%$ to $63.0 \%)$. For the education adjusted total MoCA score, the cut-off score that yielded to the best balance between sensitivity and specificity fell to less than 25 (less than or equal to 24) (61\% and 97\%, respectively; $\mathrm{AUC}=0.871, \mathrm{p}<0.001)$.

Logistic regression analyses were done to examine the statistical association between the measured, unadjusted MoCA score and categorized cognitive impairment. As seen in Table 3, the regression coefficient associated with the MoCA score in the unadjusted logistic regression model was -0.78 and the odds ratio was 0.46 . A perhaps easier way to understand this result is to say that for each unit increase in the MoCA score the odds of someone not having cognitive impairment increased 2.17 times $(1 / 0.46)$.

To develop a greater understanding of the impact of education on the primary relationship between MoCA score and disease status, education was added as a predictor variable to the regression. As seen in Table 3, education by itself was not significantly associated with disease status and did not have a significant impact on the regression coefficient associated with MoCA score.

Next, sex and age, two variables that have been shown in the literature to be predictors of disease status and that significantly differed by diagnostic group in the study population, were added to the regression model to determine the impact of these variables on the primary relationship between MoCA score and disease state. As seen in Table 3, age was not significantly associated with disease status and did not have a significant impact on the regression coefficient associated with the MoCA score. However, sex was significantly associated with disease status; the odds of males having cognitive impairment were 11.3 times those of women. Further, the regression coefficient associated with the MoCA score increased from -0.78 to -0.86 , a $10.3 \%$ change. This finding suggests that sex might have an indirect impact on predicting disease status through the MoCA score.

Table 3: Forward stepwise logistic regression models of the impact of the MoCA score on the presence of cognitive impairment

\begin{tabular}{|c|c|c|c|c|c|c|c|c|}
\hline \multicolumn{9}{|l|}{ Unadjusted Model } \\
\hline \multirow{2}{*}{$\begin{array}{l}\text { Model with } \\
\text { predictor variable }\end{array}$} & \multirow[b]{2}{*}{$\mathbf{B}$} & \multirow[b]{2}{*}{ S.E. } & \multirow[b]{2}{*}{ Wald } & \multirow[b]{2}{*}{ df } & \multirow[b]{2}{*}{ Sig. } & \multirow{2}{*}{$\begin{array}{c}\operatorname{Exp}(B) \\
\text { Odds Ratio }\end{array}$} & \multicolumn{2}{|c|}{ 95\% C.I. } \\
\hline & & & & & & & Lower & Upper \\
\hline MoCA Score & -0.78 & 0.16 & 23.3 & 1 & $<0.001$ & 0.46 & 0.35 & 0.63 \\
\hline \multicolumn{9}{|c|}{ Model Chi- $\chi^{2}=52.06,1 \mathrm{df}, \mathrm{p}<0.001$} \\
\hline \multicolumn{9}{|c|}{ Model adjusted for Education } \\
\hline \multirow{2}{*}{$\begin{array}{l}\text { Model with } \\
\text { predictor variables }\end{array}$} & \multirow[b]{2}{*}{$\mathbf{B}$} & \multirow[b]{2}{*}{ S.E. } & \multirow[b]{2}{*}{ Wald } & \multirow[b]{2}{*}{ df } & \multirow[b]{2}{*}{ Sig. } & \multirow[b]{2}{*}{$\operatorname{Exp}(B)$} & \multicolumn{2}{|c|}{ 95\% C.I. } \\
\hline & & & & & & & Lower & Upper \\
\hline MoCA Score & -0.77 & 0.16 & 22.9 & 1 & $<0.001$ & 0.46 & 0.34 & 0.64 \\
\hline Education (years) & -0.03 & 0.09 & 0.14 & 1 & 0.71 & 0.97 & 0.81 & 1.16 \\
\hline \multicolumn{9}{|c|}{ Model Chi-square $=52.20,2 \mathrm{df}, \mathrm{p}<0.001$} \\
\hline \multicolumn{9}{|c|}{ Model adjusted for Sex } \\
\hline \multirow{2}{*}{$\begin{array}{l}\text { Model with } \\
\text { predictor variables }\end{array}$} & \multirow[b]{2}{*}{$\mathbf{B}$} & \multirow[b]{2}{*}{ S.E. } & \multirow[b]{2}{*}{ Wald } & \multirow[b]{2}{*}{ df } & \multirow[b]{2}{*}{ Sig. } & \multirow[b]{2}{*}{$\operatorname{Exp}(B)$} & \multicolumn{2}{|c|}{ 95\% C.I. } \\
\hline & & & & & & & Lower & Upper \\
\hline MoCA Score & -0.86 & 0.19 & 20.48 & 1 & $<0.001$ & 0.42 & 0.29 & 0.61 \\
\hline Sex $($ Male $=1)$ & 2.42 & 0.75 & 10.58 & 1 & 0.001 & 11.27 & 2.62 & 48.49 \\
\hline \multicolumn{9}{|c|}{ Model Chi-square $=65.54,2 \mathrm{df}, \mathrm{p}<0.001$} \\
\hline \multicolumn{9}{|c|}{ Model adjusted for Age } \\
\hline \multirow{2}{*}{$\begin{array}{l}\text { Model with } \\
\text { predictor variables }\end{array}$} & \multirow[b]{2}{*}{$\mathbf{B}$} & \multirow[b]{2}{*}{ S.E. } & & & & & $95 \%$ & C.I. \\
\hline & & & Wald & df & Sig. & $\operatorname{Exp}(B)$ & Lower & Upper \\
\hline MoCA Score & -0.76 & 0.16 & 21.91 & 1 & $<0.001$ & 0.47 & 0.34 & 0.64 \\
\hline Age & 0.38 & 0.05 & 0.66 & 1 & 0.42 & 1.04 & 0.95 & 1.14 \\
\hline
\end{tabular}

MoCA: Montreal Cognitive Assessment; B = Logistic regression coefficient; S.E. = Standard Error; Wald $=$ Wald Chi-square df $=$ degrees of freedom; Sig. $=$ p-value; $\operatorname{Exp}(B)=$ Odds Ratio; 95\% C.I. $=95 \%$ confidence interval around the odds ratio. 
To look at possible confounding effect of having a control group that contained more women than men, we examined the association between age and education by sex and calculated mean MoCA scores by sex by disease state (see Table 2). There were no statistically significant differences either in mean MoCA scores or in the association between age and education by sex. As well, we ran the ROC curves independently for men and woman (see Table 2). The area under the curve was greater when using the unadjusted MoCA score for both men and women than when using the education adjusted MoCA score suggesting that the unadjusted score has better sensitivity and specificity.

\section{Discussion}

For the unadjusted total MoCA score, a cut-off score of less than 26 yielded the best balance between sensitivity and specificity in identifying people with cognitive impairment versus HC. This finding was consistent with the cut-off score identified in the original validation study. ${ }^{1}$ However, after applying the education correction suggested in the literature to the total MoCA score, the sensitivity decreased from 80 to $69 \%$ while specificity increased by only a few points, from 89 to $92 \%$. In addition, the negative predictive value fell from 0.72 to 0.63 and the area under the ROC curve fell from 0.885 to 0.871 .

The MoCA is a first-line screening tool for individuals with memory complaints, however, it does not account for premorbid levels of cognitive functioning. This is an important factor to consider, as individuals presenting to hospital-based memory disorder clinics tend to be higher functioning than similarly concerned individuals in the community are. ${ }^{9,17}$ Education has been previously shown to be correlated with the total MoCA score. It has been suggested that individuals with 12 years or less of education be given one (or even two ${ }^{10}$ ) extra point(s) on their total MoCA score. While this adjustment is a valid factor to consider, very little is known about the impact of this correction on the psychometric properties of the screening tool. Our findings suggest that the 1-point education correction would decrease the sensitivity of the screening tool: this attempt to gain specificity through education adjustment (going from $87 \%$ to $90 \%$, with the correction) had a detrimental effect on sensitivity (going from $79 \%$ to $68 \%$ ), therefore yielding more false negatives. By adding points for individuals with lower education levels, the weighting scheme associated with the tool is altered as well. Given that education level is known to moderate the risk of developing cognitive disorders, attempting to make groups of individual with lower education equivalent to a group of individuals with higher education does not make sense from a statistical perspective. As well, education level may not always reflect premorbid intellectual functioning and occupational status as opportunities to attain higher education for many individuals from previous generations may have been limited by psychosocial factors such as family income. The increased risk for false negatives due to an education correction is particularly true for individuals who score near the suggested cut-off value, ${ }^{1}$ where added points may bump a score into the normal range. In these cases, clinical judgment of premorbid functioning (e.g. intellectual function, occupational status) should be included in the interpretation of total scores both with and without the education correction. In previous generations, securing a highlevel vocational position was not completely dependent on post- secondary education. For individuals from previous generations, one's previous vocational background and lifestyle may have allowed the development of significant "cognitive reserve"18 despite a low level of education. "Cognitive reserve" can be conceptualized as a feature of brain structure and/or function that modifies the relationship between pathology and performance on cognitive tasks or clinical outcomes. ${ }^{18}$ Although the assessment of cognitive reserve is challenging ${ }^{19}$ (as it is mostly hypothetical), proposed proxy indicators of cognitive reserve include educational attainment, occupational achievement, mental activities, and premorbid IQ. ${ }^{18,20,21}$ The suggested education correction on the MoCA score refers to one of these indicators. However, we argue here that, adding an extra point to the score of an individual with a low level of education but who still have significant cognitive reserve (independent of their educational attainment) may artificially inflate their performance, and potentially lead to diagnostic inaccuracy. ${ }^{18}$ Although in some studies, level of education is positively associated with the total MoCA score, we argue that it does not always reflect pre-morbid functioning (e.g. intellectual function, occupational status) or reflect the level of cognitive reserve. We suggest that norms be developed to help guide the interpretation of the tool and that clinicians use their clinical judgment to interpret the MoCA score.

When using an education correction to augment an individual's total MoCA score another issue one needs to consider is that cut-off scores for cognitive impairment can vary depending on the population studied. For example, recent data collected revealed a mean total MoCA score of 23.4 (SD 4.0) from a community-based sample in Texas. ${ }^{22}$ A lower cut-off has also been suggested by other researchers. ${ }^{23}$ Luis and collaborators also collected data from the Southeastern U.S. and suggested that a cut-off of less than 23 should be used, to increase specificity of the tool (35 to 95 for a minimal loss in sensitivity, from 97 to 96). Indeed, if the mean MoCA score tends to be low in a given population, lowering the cut-off is likely to have a positive effect on specificity. However, if the studied population is highly educated or has significant cognitive reserve, lowering the cut-off might have a detrimental effect on sensitivity (leading to false negative diagnoses). Consequently, unless one has studied the sensitivity and specificity of a particular test with one's own population, adding extra points based on years of education to try and account for differing premorbid function may further complicate test interpretation.

One limitation of our study is that there were significant differences between the cognitively impaired group and the HC group with respect to sex and age. The effect of sex will need to be examined systematically in bigger samples. In addition, this study utilized people presenting to a tertiary care memory disorder clinic, and a group of very healthy controls. Both of these limitations could potentially limit the generalizability of the findings herein.

Nonetheless, these data show how crucial it is to develop norms to guide MoCA interpretation. Although the use of the MoCA may lead to an earlier diagnosis, it can also lead to misdiagnosis. Perhaps, in line with Dr. Nasreddine's effort to make the MoCA free and accessible, trained clinicians should systematically contribute to an open-source database with the data being analysed prospectively. This eventually could lead to 
the development of demographically adjusted norms to better guide the use of the screening tool.

\section{CONCLUSION}

We agree with previous authors on the importance of considering education when interpreting the MoCA score. ${ }^{10,11}$ However, the correlation between education and premorbid functioning is not always clear and may depend on the population. ${ }^{24}$ Data from our Memory Clinic suggest that adding an extra point for lower education levels may actually increase the rate of false negatives. For this reason, we believe MoCA scores should be interpreted both with and without the education correction and clinical intuition about premorbid function when considering diagnostic group classification. To ensure further diagnostic accuracy, we would like to stress the importance of developing norms and/or adjusted cut-off scores to guide interpretation.

\section{ACKNOWLEDGEMENTS}

The authors thank Ms. Betsy Schaefer, Research Associate for assistance with data entry for this study. Thanks also to Wilda Mardlin, Research Associate, and Christine Sleegers, nurse clinician for assistance with the Clinical Dementia Rating Scale ratings. Portions of this research were supported by seed funding from the Department of Psychiatry, Western University, London, Ontario, Canada. A special thanks to Dr. Nasreddine for creating an open-access screening tool and for his effort in constantly trying to improve it.

\section{REFERENCES}

1. Nasreddine ZS, Phillips NA, Bedirian V, et al. The Montreal Cognitive Assessment, MoCA: a brief screening tool for mild cognitive impairment. J Am Geriatr Soc. 2005;53(4):695-9.

2. Petersen RC. Clinical practice. Mild cognitive impairment. N Eng1 J Med. 2011;364(23):2227-34.

3. Petersen RC. Mild cognitive impairment as a diagnostic entity. $\mathbf{J}$ Intern Med. 2004;256(3):183-94.

4. Petersen RC, Stevens JC, Ganguli M, Tangalos EG, Cummings JL, DeKosky ST. Practice parameter: early detection of dementia: mild cognitive impairment (an evidence-based review). Report of the Quality Standards Subcommittee of the American Academy of Neurology. Neurology. 2001;56(9):1133-42.

5. Morgan DG, Crossley M, Kirk A, et al. Improving access to dementia care: development and evaluation of a rural and remote memory clinic. Aging Ment Health. 2009;13(1):17-30.

6. Folstein MF, Folstein SE, McHugh PR. "Mini-mental state". A practical method for grading the cognitive state of patients for the clinician. J Psychiatr Res. 1975;12(3):189-98.

7. Hoops S, Nazem S, Siderowf AD, et al. Validity of the MoCA and MMSE in the detection of MCI and dementia in Parkinson disease. Neurology. 2009;73(21):1738-45.

8. Videnovic A, Bernard B, Fan W, Jaglin J, Leurgans S, Shannon $\mathrm{KM}$. The Montreal Cognitive Assessment as a screening tool for cognitive dysfunction in Huntington's disease. Mov Disord. 2010;25(3):401-4.

9. Bernstein IH, Lacritz L, Barlow CE, Weiner MF, DeFina LF. Psychometric evaluation of the Montreal Cognitive Assessment (MoCA) in three diverse samples. Clin Neuropsychol. 2011;25 (1):119-26.

10. Johns E, Phillips NA, Chertkow H, et al. The Montreal Cognitive Assessment: normative data in the community. J Int Neuropsychol Soc. 2008;14 Suppl 1:i-292.

11. Phillips NA, Johns E, Chertkow H, et al. The Montreal Cognitive Assessment (MoCA): normative data in the community. Can Geriatr J. 2008;11:62.
12. Tervo S, Kivipelto M, Hanninen T, et al. Incidence and risk factors for mild cognitive impairment: a population-based three-year follow-up study of cognitively healthy elderly subjects. Dement Geriatr Cogn Disord. 2004;17(3):196-203.

13. American Psychiatric Association. Diagnostic and statistical manual of mental disorders (DSM-IV-TR). Washington, DC: American Psychiatric Association; 2000.

14. Strauss E, Sherman EMS, Spreen O. Norms election in neuropsychological assessment. A Compendium of Neuropsychological Tests. 3rd ed. Oxford, UK: Oxford University Press; 2002. p. 49.

15. Rabin LA, Saykin AJ, Wishart HA, et al. The memory and aging telephone screen: development and preliminary validation. Alzheimers Dement. 2007;3(2):109-21.

16. Morris JC. Clinical dementia rating: a reliable and valid diagnostic and staging measure for dementia of the Alzheimer type. Int Psychogeriatr. 1997;9 Suppl 1:173-6.

17. Massoud F, Devi G, Stern Y, et al. A clinicopathological comparison of community-based and clinic-based cohorts of patients with dementia. Arch Neurol. 1999;56(11):1368-73.

18. Stern Y. What is cognitive reserve? Theory and research application of the reserve concept. J Int Neuropsychol Soc. 2002;8(3):44860.

19. Jones RN, Manly J, Glymour MM, Rentz DM, Jefferson AL, Stern Y. Conceptual and measurement challenges in research on cognitive reserve. J Int Neuropsychol Soc. 2011;17(4):593-601.

20. Valenzuela MJ, Sachdev P. Brain reserve and dementia: a systematic review. Psychol Med. 2006;36(4):441-54.

21. Valenzuela MJ, Sachdev P. Brain reserve and cognitive decline: a non-parametric systematic review. Psychol Med. 2006;36(8): 1065-73.

22. Rossetti HC, Lacritz LH, Cullum CM, Weiner MF. Normative data for the Montreal Cognitive Assessment (MoCA) in a populationbased sample. Neurology. 2011;77(13):1272-5.

23. Luis CA, Keegan AP, Mullan M. Cross validation of the Montreal Cognitive Assessment in community dwelling older adults residing in the Southeastern US. Int J Geriatr Psychiatry. 2009; 24(2):197-201.

24. Nasreddine ZS, Phillips N, Chertkow H. Normative data for the Montreal Cognitive Assessment (MoCA) in a population-based sample. Neurology. 2012;78(10):765-6. 